\title{
Research on the Mechanism of Dynamic Capability Influencing Enterprise Innovation Performance in the Context of Internet
}

\author{
Rui CAO ${ }^{\mathrm{a}}$, Xiao-Ling WANG ${ }^{\mathrm{b},{ }^{*}}$ and Jie HUANG ${ }^{\mathrm{c}}$ \\ Jiangxi Normal University, No.99 Ziyang Road, Nanchang, Jiangxi Province,China \\ acaorui19940514@163.com, ’xiaoling6302@sina.com, chuangjie2624@sina.com \\ ${ }^{*}$ Corresponding author
}

Keywords: Dynamic ability, Internet enterprise, Innovation performance, Knowledge management.

\begin{abstract}
With the increasing penetration of Internet technology in decision-making activities of enterprises, the in-depth integration between the Internet and the market environment has made dynamic capabilities an essential capability for enterprises to adapt to rapidly changing markets and win innovative performance. On the basis of integrating the existing research results of dynamic capabilities and innovation performance, this paper combines the characteristics of Internet companies to logically deduce and analyze the relationship between the dynamic capabilities of Internet companies and innovation performance. Based on the dynamic capabilities and innovation performance perspectives, the mechanism of action between people. It is considered that the dynamic capabilities of Internet enterprises formed by three dimensions of identifying opportunities, integrating resources and innovating and developing which are related to the management of innovation performance. The specific ways can optimize and enhance the innovation of enterprises by innovating the enterprise culture, changing the organizational form and knowledge mana gement.
\end{abstract}

\section{Introduction}

In recent years, the global Internet technology has matured. The internet-based Internet companies are constantly emerging. They have joined the market competition. China's Internet has developed rapidly with the world's largest Internet users, the world's largest Internet infrastructure and the richest network applications.

The advent of the Internet era has had a very significant impact on the development of enterprises, making it necessary for enterprises to make the necessary management innovations to fully promote their own development. Especially in this information-based environment, the innovation performance of enterprises is particularly important for the long-term development of enterprises important. Internet business innovation performance management is still facing many problems, compared to traditional enterprises, qualitative and predictable mode of thinking and planned management and control mode, "Internet +" era background, the number of Internet companies on the market sharply increased, the industry increasingly competitive fierce. In the dynamic background of this change, Internet companies should also recognize the importance of dynamic capabilities, use the mechanism of dynamic capabilities and innovation performance, and acquire and maintain innovative performance so as to promote better development of enterprises.

\section{Literature Review and Conceptual Carding}

\section{Dynamic Capabilities}

The concept of dynamic capability has been accepted by the majority of scholars. However, there are still some differences in the definition of the concept of dynamic capability and the division of dimension between different scholars. First of all, in the definition of the concept of dynamic capabilities, Teece formally put forward the concept of dynamic capabilities for the first time in 1994, defining dynamic capabilities as the ability of enterprises to integrate, build and configure internal and external resources to meet the rapidly changing environment . Zorro and Winter 
proposed in 1997 that dynamic ability is a fixed pattern that is learned through collective activity. Winter also considers dynamic abilities as a ability to extend, modify, or create ordinary abilities. Eisenhardt and Martin proposed in 2000 that organizing dynamic capabilities is the process by which enterprises adapt or even change their markets by using their own resources, in particular, by integrating, restructuring, acquiring and releasing organizational resources to adapt to changing market conditions. This theory is the same as the redefinition of dynamic capabilities described by Teece in 1997, "The Ability of Enterprises to Adapt to Changing Environments by Integrating, Rebuilding, and Recombining External and Internal Resources and Capabilities" Generally accepted. Second, from the perspective of the dynamic capabilities, Teece, the earliest foreign scholars who put forward the analytical framework, divides the dynamic capabilities into three dimensions: process, position and path. Werner and Lavos see the ability of enterprises to acquire new external knowledge, assimilate existing internal knowledge and innovate knowledge as an important factor of dynamic capability. Zoha argued that the reconfiguration of company resources and management is an important function of dynamic capabilities. The domestic scholars analyze the dimension of dynamic ability through the aspects of ability, environment and organization. Cao Hongjun, Zhao Jianbo and others through the empirical investigation of Chinese enterprises and through data processing and analysis, put forward five dimensions of dynamic capabilities: the ability of enterprises to use dynamic information, access to dynamic resources, the ability of internal integration, release The ability of dynamic resources to coordinate with the outside of the enterprise. Luo Min through the use of fuzzy clustering analysis method to integrate the representative documents in this area for reference and proposed four dimensions: perceived market-oriented ability, business social network coordination ability, organizational learning ability and communication and coordination and integration capabilities.

To sum up, "dynamic" refers to the ability to update an enterprise in keeping with changes in the environment; "competence" emphasizes the need to integrate and allocate internal and external resources in order to adapt the enterprise to changes in the environment. The purpose of innovation is to enable businesses to respond more flexibly and quickly to their competitors than ever before in order to adapt to changing and turbulently complex market conditions. At present, in order to meet the challenge brought by market competition, innovative thinking is the driving force and necessary choice of enterprise development. How to stimulate innovation capability and enhance innovation performance are problems to be researched and solved urgently in enterprise strategic planning.

\section{Internet Companies}

Internet companies through the Internet platform, the Internet thinking, thinking mode and business model of the traditional industries subversion, so that the depth of integration of the Internet and traditional industries, and create new ecological and overall opportunities for development. Such a combination of power and opportunities will also be increasingly popular. Internet enterprises in modern sense must be dependent on the survival of the Internet industry, with Internet access services, information services, data services, online processing services as the main business, technology as the core competitiveness of the Internet industry to provide basic services Business. Based on the concept of Internet companies, Internet companies have the characteristics of network economy, dynamic complexity, efficiency and convenience and scale. The starting point of business operation and the essence of business model of Internet enterprises are based on the Internet, provide public services by using cloud computing, regard data as means of production, thereby opening up user associations, making sharing more direct and more realistic in evaluation, and enabling the Internet to make With the improvement of information utilization rate and the solution of information isolated islands in various departments of an enterprise, it can build a more concise and humane mode and effectively solve the data exchange problem.

\section{The Relationship between Dynamic Capabilities and Innovation Performance}

(1) Dynamic Capability Analysis.The Cultivation and Application of Enterprise Dynamics Ability to Help Enterprises Achieve Innovative Performance, and the Complex Relationship between Dynamic Capabilities and Enterprise Innovation Performance, Scholars put forward their own 
opinions based on different perspectives. Teece proposed in 2007 that due to the complexity of knowledge, institutional constraints and differences in individual understanding, dynamic abilities are not easily learned and reproduced. Jantunen 2012 study found that dynamic capabilities in the same industry both the existence of the same characteristics and there are similarities, of which there are similarities in perceived ability, and the ability to obtain and re-allocation of resources is different, managers should cultivate a unique dynamic business Ability to get creative. Based on the analysis of the U.S. petroleum industry in 1997, Helfat believed that the ability of dynamic research and development to promote the adaptation of enterprises to the external environment. Using the computer simulation method in 2003, Zott deduced the relationship between dynamic capabilities and firm performance and found that firms in the same industry presented significantly different performance levels due to their different dynamic capabilities. Moliterno and Wiersema put forward in 2007 that dynamic capability is the organizational ability of a company to purposely create or adjust resources, which can significantly improve the innovation performance of an enterprise. In summary, dynamic capabilities can create and maintain an enterprise's innovation performance, while dynamic capabilities are also difficult to be copied.

(2) Analysis of Innovation Performance Perspective.In recent years, academic studies have different perspectives on the definition of performance, together with the rich connotation of innovation, so scholars did not reach a consensus on the definition of innovation performance, but the three aspects that constitute the dynamic capabilities of enterprises, namely, opportunity identification, resource integration and The influence of innovation ability on the innovation performance of enterprises is more uniform. Prajogo and Ahme According to the different functions and functions of technological innovation, innovation performance can be divided into three dimensions: product innovation and application achievement, product and service innovation category, cost and speed of change. Alegre and Chiva believe that the new market openness, market share, product substitution, etc. can measure innovation performance. Kim measures product innovation performance from four aspects: product profitability, product response to customers, product brand awareness, and market competitiveness. In the past, innovation research usually regarded research and development as an important or even the only way of enterprise innovation. However, it ignored the fact that many enterprises carried out other innovation activities that are not based on $\mathrm{R} \& \mathrm{D}$ but rather performance-based market innovation, management innovation and system Innovation and so on. Christian also offers innovative management tools to enhance innovation performance in terms of teamwork, external knowledge search, human resources management and more. In summary, based on the microscopic perspective of dynamic capabilities, combined with knowledge learning and sharing, it is more beneficial to improve innovation performance with Internet companies. Internet enterprises have a wide range of technology platforms and knowledge platforms, rich management tools and methods, close interaction between enterprises and other organizations based on cooperative innovation, activities that help enterprises to update and re-integrate resources, and the dynamic capabilities of Knowledge changes, knowledge innovation can promote the construction and development of dynamic capabilities. Therefore, in order to develop and tap the potential of an organization, the enterprise needs a series of management abilities to acquire, absorb, create and integrate innovative knowledge. These innovations based on dynamic capabilities not only affect the realization of innovation performance but also optimize the dynamic capabilities of enterprises.

\section{The Dynamic Capabilities of Internet Companies and the Realization of Innovation Performance}

\section{The Dynamic Capabilities of Internet Companies}

(1)Identify opportunities. With the help of scientific and technological means, Internet companies have the ability to quickly anticipate changes in the environment and search, perceive and identify market opportunities in a changing environment in order to promote the dynamic capability of enterprises to make corresponding strategic adjustments within the enterprise so that the internal 
Structure to adapt to the dynamic changes in the external environment, seize the opportunity, and then in the fierce competition in innovation, focusing on innovation performance evaluation and promotion. When enterprises identify certain development opportunities in the market environment, they should carry out strategic analysis in light of the external environment and internal environment of the enterprises, make rational organizational structure changes and deploy development strategies in a timely manner.

(2)Integration of resources. Resource integration refers to enterprises through value analysis, re-allocation of resources to form a new capacity and resource mix. First of all, based on the acquisition of information and data analysis, Internet companies integrate their existing internal resource capabilities to form a unified external core competitiveness. Secondly, when enterprises need to realize their core competencies required by established strategies, they should adopt the methods of internal development, mergers and acquisitions and knowledge alliances to introduce external resources while appropriately coordinating and integrating to internalize resources for their development. In addition to the above two ways of integrating resources (integrating internal resources within and outside enterprises, and integrating resources inside and outside the enterprise), Internet enterprises may also face the integration of corporate culture, values and business philosophy when there is a huge change in the external environment. All in all, successful integration helps companies take full advantage of resources to achieve business goals and continue to grow, achieving and sustaining the company's innovation performance.

(3) Innovation and development. In the next few years, all those who are just pursuing product profits will continue to become the processors of mobile Internet ecological-brands, losing the right to operate their brands in the mobile Internet era. When the ecology of traditional industries is broken, the opportunities to build a new Internet ecological-brand will be those that first understand and act on the future trends. Ecosystem competition is very different from platform competition. Competition between platform-based enterprises is the scale and openness, these are more inclined to the business level, and the competition between ecosystems is connected species richness and dependence. For example, many enterprises are still keen on using the Internet as a sales channel and communication platform. They are also staying on the electricity supplier business. They rely on the "brush volume" and are spread by "navy forces." In the process, they are continuously entangled. However, Alibaba, Tencent, Millet and other Internet giants have begun to build the Internet ecosystem, covering manufacturing ecology, service industry ecology, agricultural ecology, financial ecology, social ecology, content ecology. From this it can be seen that innovation and development are very important links in dynamic capabilities. Only through innovation and development can we truly adapt to the changing environment, so as to build the best business model for enterprises and to maintain a new advantage based on the original Competitiveness.

\section{The Realization of Internet Business Innovation Performance}

(1) Innovative corporate culture.The innovation of corporate culture is an important condition for the formation of dynamic capabilities. The construction of dynamic capabilities of enterprises requires the support of a strong and innovative corporate culture. Corporate culture is closely linked to the company's strategy and performance, corporate culture simplifies information processing, complements formal controls, fosters teamwork and reduces the cost of bargaining, thus constituting the primary means of creating value for the business. Corporate culture is also an important condition for improving innovation performance. First of all, the corporate culture must be unique. If an enterprise's culture is the same as most of the enterprises in the market, it often reflects the influence of national or regional culture or a series of industry norms, then it can not bring about innovation. Second, the corporate culture must be hard to imitate. If the corporate culture is easily imitated, the innovation performance brought about by the culture will be quickly offset.

Corporate culture is a common philosophy of business members, ideology, values, beliefs, assumptions, expectations and ethics. Among them, the values are the core of the enterprise culture, innovation and change are the core elements of the enterprise value concept system. If the 
innovative values can be formed within the enterprise and endorsed by all the employees in the enterprise, the innovation system and code of conduct will be established and perfected and operate efficiently in the process of implementation. This will be a strong support for the formation of the dynamic capabilities of enterprises. Therefore, through the improvement of the value system, Internet companies must recognize that innovative culture is the soul of enterprise development and timely update their strategic concepts so as to update and rebuild their dynamic capabilities.

(2) Innovative organizational form. Organizational structure is the various division of labor and coordination system that the organization carries out to achieve the common goal. The adjustment and perfection of the organizational structure is an important part of the strategy implementation. Under the background of the Internet age, in face of the unpredictable competitive environment, decentralized, flattened and low-standard "border less" organizations or "hypertext" organizations have increasingly proved to be conducive to the development of enterprises. Enterprises should comply with Environmental Change and Organizational Change Trends Build a new organizational form that nurtures the dynamic capabilities of your business to drive innovation performance management.

In view of the characteristics of Internet companies and the need of cultivating the dynamic capabilities of enterprises, enterprises can choose matrix organizational structure and organizational incentive system to cultivate their dynamic capabilities. Among them, the matrix organizational structure is designed to deal with the complex and volatile issues in the project, this structure is very flexible, and can effectively strengthen the linkages between projects, give priority to the development of business priorities, to avoid functional type Structure is not paying enough attention to the market and products. In a dynamic environment, the matrix organizational structure has greater flexibility and helps various professionals to help each other, inspire each other, enhance horizontal ties, and make full use of professional equipment and personnel to achieve flexible sharing of human resources. The organizational incentive mechanism aims at overcoming the inertia influence in the organization, realizing the full participation by overcoming the staff's cognitive inertia, and making the organization flexible and flexible. Incentive mechanism for enterprise employees take the initiative to identify problems and seek opportunities to provide motivation to support the activation of dynamic capabilities of enterprises to play an incentive role. In the enterprise established entrepreneur-led innovation and tolerance-based incentive mechanism, the enterprise will be full of entrepreneurial and innovative atmosphere, so as to inspire staff to keep making progress, and actively identify opportunities and dynamic match with the enterprise resources, thus activating the dynamic ability. To be specific, we can encourage employees to bravely innovate and establish the necessary first failure tolerance mechanism by improving the management methods of talents or selecting reasonable incentives, so that the incentive mechanism becomes the way of generating the dynamic capabilities of enterprises and thus the goal of improving innovation performance.

(3)Knowledge Management.The essence of dynamic capability is knowledge. Knowledge management helps enterprises to share, acquire and create new knowledge so as to improve their dynamic capabilities. Knowledge management in various forms, the most common way through knowledge alliance to achieve, refers to the enterprise in the process of achieving the strategic objectives of innovation, in order to share knowledge resources, promote knowledge flow and create new knowledge, and other enterprises, universities and research institutes Between the various forms of contract or equity formed by the complementary advantages of risk-sharing network organizations. Under the Internet age, the sharing of knowledge is crucial for the development of the dynamic capabilities of enterprises. First of all, knowledge management helps the member companies to improve the dynamic coordination and integration ability within the enterprise after a long period of extensive cooperation, communication and knowledge sharing, so as to improve their dynamic capabilities. Second, knowledge management helps to improve the learning abilities of member firms and helps organizations build learning organizations, thereby finding new opportunities to nurture the dynamic capabilities of firms. At the same time, knowledge management is helpful for alliance partners to learn from each others' tacit knowledge based on 
different knowledge bases, to create a spiraling knowledge and to convert the tacit knowledge into more shared explicit knowledge and implicitness Knowledge, and thus enhance the dynamic capabilities of enterprises. In addition, knowledge management promotes the knowledge transfer of enterprises, which obscures the traditional distinct boundaries of enterprises, and the original closed boundaries become "porous" and easily pass, thus weakening the restraint effect of enterprise boundaries on the movement of tacit knowledge At the same time, knowledge management can make multiple enterprises share the cost of sharing information and knowledge, thus reducing the financial pressure on the enterprise. On the basis of promoting the formation of dynamic capabilities and innovation performance, strengthening dynamic capabilities plays a positive role in the management of innovative performance of enterprises, Create market advantage, help to help enterprises in the fierce market competition to achieve the desired goal.

\section{Acknowledgement}

This research was supported by the project of National Natural Science Foundation of China (71662018) and was a phased achievement of "Microscopic Mechanism for the Formation of Dynamic Capabilities of Enterprises: From the Perspective of Innovative Flexible Human Resource Management".

This paper is also a milestone achievement of the Research on the Formation Mechanism of Dynamic Capabilities of Enterprises Based on Flexible Human Resource Management in Humanities and Social Sciences Research Project of Universities in Jiangxi Province (GL161002).

\section{References}

[1] Helfat.C.E. and Peteraf, M.A. ,The Dynamic Resource-Based View: Capability Lifecycles,J.Stratigic Management Journal.24(2003), 997-1010.

[2] Michael Porter.,Competitive Strategy,M.Beijing: Mechanical Industry Press, 2009, 131-152.

[3] Teece.D.J. ,Explicating Dynamic Capabilities: The Nature and Micro-Foundations of Enterprise Performance,J.Strategic Management Journal.28(2007), 1319-1350.

[4] Wang C.L.and Rafiq.M.,Dynamic Capabilities and Firm Performance.,J.British Journal of Management.26(2015), 26-44.

[5] Zott.C.,Dynamic Capabilities and the Emergence of the Industry Differential firm Performance:Insight from Simulation Study,J.Stratigic Management Journal.24(2003), 97-125.

[6] Zollo.M. and Winter, S.,Deliberate Learning and the Evolution of Dynamic Capabilities, J.Organization Science.13(2002), 339-351.

[7] Du Junyi,Effects of SMEs' Dynamic Capabilities on Innovation Performance,J.Science Management.1(2017),26-31.

[8] Luo Min,Theoretical structure and components of dynamic capabilities of enterprises ,J. Business Administration.1(2009),75-86.

[9] Liu Gang,An Empirical Study of the Impact of Dynamic Capabilities on Firm Performance,J. Economic Theory and Business Management.33 (2013),83-94.

[10]Wu Hang, Characterization of Dynamic Capabilities and Its Impact on Innovation Performance - A Reflection on the Classic Definition of Teece ,J.Management Review.28 (2016),77-83.

[11]Xue Jie,Study on the relationship between dynamic learning ability and innovation performance in the turmoil of technology and market environment,J .Science \& Technology Progress and Policy.32 (2015),99-104. 
[12]Zhao Jianbo,Study on the Dimensionality of Dynamic Capabilities ,J. Science of Science.27 (2009): 36-44. 